\title{
Speech pathology students' perceived learning outcomes following participation in a fluency booster program
}

\author{
A. Penman, N. Brown \& A. E. Hill
}

\begin{abstract}
Introduction: Intensive fluency programs are a service delivery option for adults and adolescents who stutter and can act as clinical education opportunities for speech pathology students. Previous research established that student participation in a 5-day intensive fluency program resulted in increased student confidence, knowledge and interest while decreasing student anxiety. Though effective, this service delivery model is time and resource intensive for students and clients alike. The aim of this study was to investigate students' levels of confidence, knowledge, interest and anxiety pre- and post-participation in a shorter, 2-day intensive fluency booster program.
\end{abstract}

Methods: Participants in this study were speech pathology students at an Australian university. This mixed methods study used pre- and post-program Likert scale surveys to explore students' perceptions of their learning. In addition, students' general perceptions of the program were examined through responses to open-ended questions. Quantitative results were analysed using the Wilcoxon signed ranks test, and results of the qualitative data were analysed using content analysis.

Results: Data was obtained from 68 students. Statistically significant changes $(p<.001)$ were observed on all surveyed items of confidence, knowledge, interest and anxiety. In their responses to open-ended questions, students reported that the booster program was well-structured and offered supported learning opportunities and a valued means to interact with clients who stutter. Recommendations for program improvements were noted.

Conclusions: Results from this study indicate that a 2-day fluency booster program may be an appropriate clinical learning opportunity for speech pathology students.

\footnotetext{
Correspondence

Adriana Penman

Discipline of Speech Pathology

School of Health and Rehabilitation Sciences

The University of Queensland

Therapies Building (Building 84A)

St Lucia Campus

St Lucia, Queensland 4072

Australia

Tel: +61 733652306

Fax: +61 733651877

Email: a.penman1@uq.edu.au
} 
Keywords: clinical education; speech pathology; students; stuttering; fluency disorders Discipline of Speech Pathology, School of Health and Rehabilitation Sciences, The University of Queensland, Australia

\section{Introduction}

Stuttering is reported to occur in approximately $0.72 \%$ of the population, with a higher prevalence of stuttering in younger children than adolescents and adults (Craig, Hancock, Tran et al., 2002). If targeted early, childhood stuttering can be remediated (Onslow et al., 2012). However, for adults and adolescents who stutter (AWS), there are likely to be negative impacts on quality of life (Beilby, 2014), mental health concerns (Craig, Blumgart, \& Tran, 2009), job prospect issues (Klein \& Hood, 2004) and social anxiety (Blumgart et al., 2010). Consequently, it is important that speech pathology services are available for AWS in order to reduce stuttering and, therefore, mitigate the impact.

Services for AWS in Australia are currently restricted, partially due to the limited availability of public funding and under-resourcing of speech pathologists nationally (The Senate, 2014). This issue is further compounded by reports that speech pathologists feel that they lack preparation for (Kelly et al., 1997) and comfort in (Lee, 2014; Mavis et al., 2013) working with those who stutter, more so than working with other communication disorders, such as speech and articulation disorders (Crichton-Smith et al., 2003; Mavis et al., 2013). Given practitioners' lack of comfort, it is unsurprising that speech pathology students are also reported to harbour negative self-beliefs towards working with AWS, such as reduced confidence in stuttering management (Cardell \& Hill, 2013).

Speech pathology students are service providers of the future and, as such, require opportunities to develop confidence in their knowledge and clinical skills in the area of fluency upon graduation. A mixed-methods pilot study by Koutsodimitropoulos et al. (2016) reported that students felt that they lacked preparation for working with those who stutter clinically. In addition, the authors reported that students felt they had adequate theoretical knowledge about stuttering however lacked confidence translating this theory into practice. Clinical exposure to clients who stutter was identified by students as integral to having confidence and competence working in this area. Although this study had a small sample size of 13 , and its fluency program participants, content and structure were not detailed, it highlighted the importance of providing students with fluency-related clinical experiences in order to increase their confidence in their clinical abilities.

Confidence and belief in one's ability to complete and achieve specific tasks is described as self-efficacy (Bandura, 1977). A study by Pasupathy and Bogschutz (2013) investigated the clinical self-efficacy of first- and second-year students in a US graduate speech pathology program. There was a positive relationship between the graduate students' perceived self-efficacy and clinical performance, with perceived self-efficacy increasing in proportion to increased direct clinical hours (Pasupathy \& Bogschutz, 
2013). Accordingly, providing students with clinical experiences that will increase their self-efficacy and confidence in their clinical skills is an appropriate objective, but sourcing sufficient placements to enable this is a challenge (SPA, 2018). Additional placement opportunities must be developed to redress this shortage.

Programs delivered in an intensive model can provide learning opportunities and increase student self-efficacy (Flasch et al., 2017). Intensive therapy programs are widely used across speech pathology to support adults with communication disorders (Block et al., 2005; L. Brown et al., 2016; Cardell \& Hill, 2013; Irani et al., 2012; Park et al., 2015; Rodriguez et al., 2013; Rose et al., 2013). While a range of intensive programs have included students in their service delivery (Block et al., 2005; L. Brown et al., 2016; Cardell \& Hill, 2013; Irani et al., 2012; Rodriguez et al., 2013), limited research exists within the field of speech pathology addressing student outcomes following participation in such a program (Cardell \& Hill, 2013).

Cocks et al. (2014) investigated student learning outcomes after participation in a 5-day dysphagia intensive placement. Findings from this study revealed that students perceived they had increased knowledge, experience, awareness of clinical skills, confidence and competence in managing clients with dysphagia after participating in this intensive clinic. Similar outcomes were reported from a study by Cardell and Hill (2013). Students rated their confidence, knowledge, interest and anxiety levels before and after participating in a 5-day student-led intensive smooth speech clinic. Results indicated that students' confidence, knowledge and interest scores increased significantly while their perceived anxiety levels decreased (Cardell \& Hill, 2013). While the 5-day service delivery option may hold promise for positive learning outcomes for students, this program structure is time and resource consuming for students, educators and clients alike. Consequently, a shorter intensive fluency program may be more acceptable. However, such a program's capacity to yield comparable student learning outcomes to those obtained in the study by Cardell and Hill (2013) is unknown.

Therefore, this study investigated students' perceptions of a 2-day intensive fluency booster program for AWS. Specifically, this research aimed to determine if participation in this program increased students' perceived levels of confidence, knowledge and interest and decreased their anxiety. In addition, the study explored students' views on what they liked and did not like about the program, and possible improvements that could be made.

\section{Methods}

Ethical clearance for this study was acquired through The University of Queensland Human Research Ethics Committee (approval number 2009000052). This mixedmethods study adopted a concurrent triangulation design (Creswell et al., 2002), consisting of quantitative data collection from pre- and post-program surveys and qualitative data obtained from responses to open-ended questions within the postprogram survey. Data was collected over six iterations of the 2-day fluency booster program between 2014 and 2016. 


\section{Participants}

Seventy-one final-year speech pathology students (18 graduate-entry masters and 53 undergraduate) from The University of Queensland volunteered to participate in the fluency booster program. All students had previously completed a university course in fluency disorders, which focused on academic and in-class practical tasks only. There were 66 females and five males aged between 20 years and 43 years (mean 24 years; $S D=4.21$ years). This gender balance is reflective of the speech pathology profession in Australia (HWA, 2014). Students were invited to participate in the current study on the fluency booster program training day (described below) and were advised that their consent to participate in the study was voluntary and involved the completion of a preand post-program survey only. They were also informed that their clinical skills would not be formally assessed and that they were free to withdraw from the study at any time. Students provided written consent to participate in the study. They were excluded from the study if they did not attend the training day conducted prior to the fluency booster program and each of the two program days.

\section{Procedure}

Prior to the fluency booster program, students participated in a 1-day training session with two speech pathologists experienced in fluency management (first author and another clinician). This session focused on revising fluency disorders theory and the practical requirements of the program, which included identifying stuttering behaviours, measuring syllables per minute (SPM), measuring percent syllables stuttered (\%SS) and practising smooth speech skills, with feedback provided by the clinicians. The students were given access to audio exemplars to facilitate independent home-based practice of smooth speech and rating prior to the program.

Clients attended the fluency booster program for 2 days and participated in 8 hours per day of individual and group therapy with student clinicians who worked individually or in a pair. They were supervised by speech pathologists at all times either within the clinic room or through synchronous viewing in a monitor room. The supervision ratio of speech pathologist to student was typically one to four (1:4).

The fluency booster program was developed and adapted from various smooth speech programs, such as the La Trobe program (Block et al., 2005), and incorporated known program components of easy onsets, group therapy and cognitive restructuring. Smooth speech is a form of speech restructuring, a fluency treatment that makes changes to a person's breathing, phonation and articulation in order to change speech output (L. Brown et al., 2016). It typically involves teaching clients to use gentle onsets, slide into words, elongate vowels and run all words together at increasing speech rates (Block et al., 2005).

Clients were adolescents (between 12-17 years of age) and adults who presented with fluency disorders and had previously received speech restructuring therapy. The clients completed tasks including monologue, conversational and reading tasks, according to pre-set criteria achievement. These occurred at different speaking rates-beginning 
at 100-120 SPM, progressing to 150 SPM and, when able, using "comfort rate", defined as the rate at which a client is able to maintain fluency with natural sounding speech using smooth speech techniques (Block et al., 2005). Transfer activities, such as making phone calls, were introduced on day one, along with relaxation and cognitive restructuring activities. Cognitive restructuring is based on cognitive behavioural therapy and requires the client to challenge their negative beliefs about stuttering (Menzies et al., 2009).

\section{Data collection tools}

Data was gathered using two surveys, which investigated the students' confidence, knowledge, interest and anxiety working with AWS. Students completed the first survey at the beginning of the training session and the second after the program concluded. The surveys used in this study were adapted from those used by Cardell and Hill (2013), as these questions were considered suitable to provide specific and relevant information about students' confidence, knowledge, interest and anxiety. The pre-program survey contained 22 items, with responses made on 5-point Likert scales. Students' confidence was explored in 14 statements, where a rating of 1 represented strongly disagree and a rating of 5 represented strongly agree. Students rated their knowledge in six statements, on a scale where 1 represented no knowledge and 5 represented very good knowledge. The remaining two questions addressed students' interest and anxiety, where a rating of 0 represented not interested/not anxious and a rating of 4 represented extremely interested/ extremely anxious. The post-program survey included the same 22 items as the first survey, however it also incorporated four open-ended questions exploring what students liked most/least about the program and their recommendations for improvements.

\section{Data analysis}

Descriptive statistics were used to compare the medians and ranges of the students' pre- and post-program self-ratings. The Wilcoxon signed rank test was used to analyse the results (Statistical Package for the Social Sciences (SPSS) version 19) and highlight any significant differences between pre and post scores. A $p$-value of $p<.01$ denoted statistical significance in this study.

Content analysis (Graneheim \& Lundman, 2004) was used to analyse the qualitative data from responses to open-ended questions. Students' responses to each question were analysed into meaning units, defined as "words, sentences or paragraphs containing aspects related to each other through their content and context" (Graneheim \& Lundman, 2004, p. 106). Meaning units were reduced into condensed meaning units and codes. The final codes were clustered to create sub-categories and categories. Rigour in analysis of the data obtained in this study was achieved through the following method: the second author initially coded all data into meaning units; discussion between all authors followed, related to translation of meaning units into codes; clustering of codes into sub-categories was then undertaken by the second author; refinement of the coded data was completed through consensus from all authors; and the final phase of clustering sub-categories into categories was again undertaken by all authors. 


\section{SPEECH PATHOLOGY STUDENTS' PERCEIVED LEARNING OUTCOMES}

\section{Results}

\section{Quantitative data}

Data sets were available from 68 participants. Not all participants completed response ratings for each survey section, therefore complete data sets differ in number across sections. Statistically significant increases in confidence were observed from pre- to post-program in all clinical skills related to stuttering assessment and management (see Table 1). The largest change in pre- to post-program confidence scores was reported by students in their responses to statements relating to: conduct an assessment, use smooth speech, provide smooth speech, teach on error, mentor other clinicians, and use cognitive restructuring.

\section{Table 1}

Students' (n=68) Median Pre-Post Program Ratings of Confidence Levels in Working With Adults and Adolescents Who Stutter

\begin{tabular}{|c|c|c|c|c|c|}
\hline \multirow{2}{*}{$\begin{array}{l}\text { Survey statements } \\
\text { "I feel confident in my ability to ..." }\end{array}$} & \multicolumn{2}{|c|}{$\begin{array}{l}\text { Pre-program } \\
\text { Ratings** }\end{array}$} & \multicolumn{2}{|c|}{$\begin{array}{l}\text { Post-Program* } \\
\text { Ratings }\end{array}$} & \multirow[t]{2}{*}{$\begin{array}{l}\text { Wilcoxon Signed Rank } \\
\text { Test Values }\end{array}$} \\
\hline & Median & Range & Median & Range & \\
\hline $\begin{array}{l}\text { Establish rapport with a client who } \\
\text { stutters }\end{array}$ & 4 & $(2-5)$ & 5 & $(4-5)$ & $z=-6.951, p<.001^{* *}$ \\
\hline $\begin{array}{l}\text { Interview a client who stutters about } \\
\text { personal information }\end{array}$ & 4 & $(2-5)$ & 5 & $(4-5)$ & $z=-6.675, p<.001^{* *}$ \\
\hline $\begin{array}{l}\text { Interact in a professional manner with a } \\
\text { client who stutters }\end{array}$ & 4 & $(2-5)$ & 5 & $(4-5)$ & $z=-6.517, p<.001^{* *}$ \\
\hline $\begin{array}{l}\text { Conduct an assessment with a client } \\
\text { who stutters }\end{array}$ & 2 & $(1-4)$ & 4 & $(4-5)$ & $z=-6.999, p<.001^{* *}$ \\
\hline Identify and classify stuttering behaviours & 3 & $(2-4)$ & 4 & $(3-5)$ & $z=-6.472, p<.001^{* *}$ \\
\hline Calculate stuttering frequency & 3 & $(1-5)$ & 4 & $(3-5)$ & $z=-6.710, p<.001^{* *}$ \\
\hline $\begin{array}{l}\text { Accurately rate the speech of a client } \\
\text { who stutters }\end{array}$ & 3 & $(1-4)$ & 4 & $(3-5)$ & $z=-6.754, p<.001^{* *}$ \\
\hline $\begin{array}{l}\text { Select the appropriate treatment program } \\
\text { for a client who stutters }\end{array}$ & 3 & $(1-4)$ & 4 & $(2-5)$ & $z=-6.460, p<.001^{* *}$ \\
\hline $\begin{array}{l}\text { Use smooth speech skills effectively to } \\
\text { assist treatment }\end{array}$ & 2 & $(1-4)$ & 4 & $(1-5)$ & $z=-7.069, p<.001^{* *}$ \\
\hline $\begin{array}{l}\text { Provide smooth speech treatment to a client } \\
\text { who stutters }\end{array}$ & 2 & $(1-4)$ & 4 & $(3-5)$ & $z=-7.114, p<.001^{* *}$ \\
\hline $\begin{array}{l}\text { Teach on error when smooth speech } \\
\text { is incorrect }\end{array}$ & 2 & $(1-4)$ & 4 & $(2-5)$ & $z=-7.006, p<.001^{* *}$ \\
\hline $\begin{array}{l}\text { Write a report outlining assessment and } \\
\text { treatment for a client who stutters }\end{array}$ & 3 & $(1-4)$ & 4 & $(2-5)$ & $z=-5.292, p<.001^{* *}$ \\
\hline $\begin{array}{l}\text { Mentor other clinicians who are } \\
\text { inexperienced in stuttering management }\end{array}$ & 2 & $(1-4)$ & 4 & $(1-5)$ & $z=-7.100, p<.001^{* *}$ \\
\hline $\begin{array}{l}\text { Use cognitive restructuring strategies to } \\
\text { manage client's negative self-perceptions } \\
\text { due to their stutter }\end{array}$ & 2 & $(1-4)$ & 4 & $(2-5)$ & $z=-6.224, p<.001^{* *}$ \\
\hline
\end{tabular}

* Responses were obtained on a scale of 1 to 5 where $1=$ strongly disagree and $5=$ strongly agree.

** = statistically significant result $p<.01 ; p$-values are two-tailed. 
Statistically significant increases between pre- and post-program perceived knowledge levels related to stuttering assessment and treatment are detailed in Table 2. Knowledge of service delivery formats represented the largest change in pre- to post-program knowledge scores.

\section{Table 2}

Students' (n=68) Median Pre-Post Program Ratings of Level of Knowledge About Stuttering

\begin{tabular}{|c|c|c|c|c|c|}
\hline \multirow[t]{2}{*}{ Areas of Knowledge } & \multicolumn{2}{|c|}{$\begin{array}{l}\text { Pre-program } \\
\text { Ratings* }\end{array}$} & \multicolumn{2}{|c|}{$\begin{array}{l}\text { Post-Program* } \\
\text { Ratings }\end{array}$} & \multirow[t]{2}{*}{$\begin{array}{l}\text { Wilcoxon Signed Rank } \\
\text { Test Values }\end{array}$} \\
\hline & Median & Range & Median & Range & \\
\hline The disorder of stuttering & 3 & $(2-5)$ & 4 & $(3-5)$ & $Z=-5.873, p<.001^{* *}$ \\
\hline The assessment of stuttering behaviours & 3 & $(2-4)$ & 4 & $(3-5)$ & $z=-6.681, p<.001^{* *}$ \\
\hline The treatment of stuttering & 3 & $(2-5)$ & 4 & $(2-5)$ & $z=-6.811, p<.001^{* *}$ \\
\hline The impact that stuttering has on a person & 4 & $(2-5)$ & 5 & $(3-5)$ & $z=-5.945, p<.001^{* *}$ \\
\hline The technique of smooth speech & 3 & $(2-5)$ & 4 & $(2-5)$ & $z=-7.012, p<.001^{* *}$ \\
\hline $\begin{array}{l}\text { The service delivery formats for stuttering } \\
\text { intervention }\end{array}$ & 2 & $(1-4)$ & 4 & $(3-5)$ & $z=-6.990, p<.001^{* *}$ \\
\hline
\end{tabular}

* Responses were obtained on a scale of 1 to 5 where $1=$ strongly disagree and $5=$ strongly agree.

${ }^{* *}=$ statistically significant result $p<.01 ; p$-values are two-tailed.

Students' $(\mathrm{n}=68)$ interest in working with AWS increased significantly $(z=-4.811$, $p<.001)$, and students' $(\mathrm{n}=62)$ level of anxiety decreased significantly $(z=-6.099$, $p<.001)$ from pre-program to post-program ratings.

\section{Qualitative data}

Responses to open-ended questions were obtained from 66 participants and are outlined in detail below.

\section{What did you like most about the booster program?}

Responses to this question yielded three categories from 264 codes and eight subcategories (see Table 3). Firstly, students liked the learning opportunities provided by the program. The opportunity for students to perform fluency-related tasks was identified as key to student learning, enabling students to "interact with clients of all ages and severity levels, to be exposed to many different aspects of stuttering and the impact it can have" (S116) and "gain experience in fluency treatment" (S88). Participation in the fluency booster program enabled students to be exposed to stuttering. Students were able to "see the positive impact the program has on the participants" (S65) and "see how the work we were all doing was helping in the real world" (S104). Some students explained that the fluency booster program provided the opportunity to gain knowledge, "[I] learnt so much that couldn't be learnt in a lectureltextbook" (S72), and confidence, "the confidence you gain to take on a fluency client" (S109). 
Satisfaction with the format of the fluency booster program was another category identified by students. The activities within the program were positively perceived, including group sessions, "Group sessions were really great for getting to know the other clients better" (S105), and functional components of the program, "I loved the transfer tasks" (S104). Students also stated that they enjoyed the program's design, "the intensive allowed me to learn on the fly" (S84) and structure, "the clear structure that could be modified to suit the client" (S123).

Support received throughout the fluency booster program was the final category revealed in response to this question. Students identified support from others, such as "support and useful advice and strategies from SLPs when struggling" (S66), and support from other students, "It was good to have another student's input" (S83), as positive aspects of the program. Finally, students reported they liked the program's supportive environment, "Booster is a positive and supportive environment" (S45).

\section{Table 3}

Categories, Sub-categories and Codes From Student Responses to Post-program Survey Question "What Did You Most Like About the Program?"

\begin{tabular}{|c|c|c|c|}
\hline \multirow{2}{*}{$\begin{array}{l}\text { Category } \\
\text { Sub-categories }\end{array}$} & \multicolumn{3}{|c|}{ Liked learning opportunities ( $n=143$ ) } \\
\hline & $\begin{array}{l}\text { Liked the opportunity to } \\
\text { perform fluency related tasks } \\
\text { ( } \mathrm{n}=69 \text { ) }\end{array}$ & $\begin{array}{l}\text { Liked the opportunity to } \\
\text { be exposed to fluency } \\
\text { experiences }(n=44)\end{array}$ & $\begin{array}{l}\text { Liked the opportunity to gain } \\
\text { knowledge and confidence } \\
(\mathrm{n}=30)\end{array}$ \\
\hline Codes & $\begin{array}{l}\text { Liked the opportunity for } \\
\text { students to interact with } \\
\text { clients }(n=34) \\
\text { Liked the opportunity to } \\
\text { provide therapy }(n=10) \\
\text { Liked the opportunity to work } \\
\text { individually with the client } \\
(n=9) \\
\text { Liked the opportunity to } \\
\text { practise smooth speech } \\
(n=5) \\
\text { Liked the opportunity to gain } \\
\text { general fluency experience } \\
(n=5) \\
\text { Liked the opportunity for } \\
\text { clients to interact with clients } \\
(n=4) \\
\text { Liked the opportunity to } \\
\text { develop assessment skills } \\
(n=2)\end{array}$ & $\begin{array}{l}\text { Liked the opportunity to see } \\
\text { client improvement }(n=27) \\
\text { Liked the opportunity to see } \\
\text { the application of treatment } \\
(n=6) \\
\text { Liked the opportunity to be } \\
\text { exposed to stuttering and } \\
\text { how it presents }(n=6) \\
\text { Liked the opportunity to see } \\
\text { the outcomes of speech } \\
\text { pathology service }(n=5)\end{array}$ & $\begin{array}{l}\text { Liked the opportunity to } \\
\text { learn more about stuttering } \\
\text { assessment and management } \\
(n=9) \\
\text { Liked that the program } \\
\text { provided the opportunity to } \\
\text { extend learning }(n=6) \\
\text { Liked the opportunity to learn } \\
\text { from others }(n=7) \\
\text { Liked the opportunity to gain } \\
\text { confidence }(n=4) \\
\text { Liked the opportunity to see } \\
\text { student improvement }(n=4)\end{array}$ \\
\hline
\end{tabular}




\section{SPEECH PATHOLOGY STUDENTS' PERCEIVED LEARNING OUTCOMES}

\section{Table 3}

Categories, Sub-categories and Codes From Student Responses to Post-program Survey Question "What Did You Most Like About the Program?" (contd.)

\begin{tabular}{|c|c|c|c|c|}
\hline \multirow{2}{*}{$\begin{array}{l}\text { Category } \\
\text { Sub-categories }\end{array}$} & \multicolumn{4}{|c|}{ Liked the format of the program $(n=93)$} \\
\hline & $\begin{array}{l}\text { Liked the program activities } \\
(\mathrm{n}=35)\end{array}$ & \multicolumn{2}{|c|}{$\begin{array}{l}\text { Liked the design of the } \\
\text { program }(n=26)\end{array}$} & $\begin{array}{l}\text { Liked the structure of the } \\
\text { program }(n=32)\end{array}$ \\
\hline Codes & $\begin{array}{l}\text { Liked the group involvement } \\
\text { ( } n=17) \\
\text { Liked the functional tasks } \\
(n=12) \\
\text { Liked hearing client stories } \\
(n=4) \\
\text { Liked the training day }(n=2)\end{array}$ & \multicolumn{2}{|c|}{$\begin{array}{l}\text { Liked the program's intensive } \\
\text { design }(n=17) \\
\text { Liked the program's hands-on } \\
\text { approach }(n=9)\end{array}$} & $\begin{array}{l}\text { Liked that the program had a } \\
\text { set structure }(n=26) \\
\text { Liked that the program had a } \\
\text { flexible structure }(n=6)\end{array}$ \\
\hline Category & \multicolumn{4}{|c|}{ Liked the support received throughout the program $(n=28)$} \\
\hline Sub-categories & \multicolumn{2}{|c|}{$\begin{array}{l}\text { Liked the support from others in the program } \\
(\mathrm{n}=22)\end{array}$} & \multicolumn{2}{|c|}{ Liked the supportive environment $(n=6)$} \\
\hline Codes & \multicolumn{2}{|c|}{$\begin{array}{l}\text { Liked the support from the CEs }(n=12) \\
\text { Liked the positivity brought by the CEs }(n=5) \\
\text { Liked the support from other students in the } \\
\text { program }(n=5)\end{array}$} & \multicolumn{2}{|c|}{ Liked the supportive environment $(n=6)$} \\
\hline
\end{tabular}

Note: Numbers in brackets are the number of condensed meaning units per category, sub-category and code.

\section{What did you like least about the booster program and how could it be improved?}

Responses to this question yielded two categories from 122 codes and four subcategories relating to the program's format, content and timing (see Table 4). Students did not like the reduced amount of time given to preparation and reported a dislike of feeling unprepared, "I felt a bit unprepared with my smooth speech skills" (S54). Students also disliked some aspects of the program's design. They reported that the intensity of the program was tiring and stressful, "I felt so tired at the end of the day" (S87), and that the program "felt a little rushed" (S65) and should be extended in length, "make it a five-day program" (S63). Students disliked that "there was no time allocated for practising with our clinic partners as part of the training day" (S60) and suggested redesigning the training day, "I feel that training hours would best be utilised by smooth speech practice and feedback on smooth speech" (S74). The inclusion of group tasks within the program for clients was perceived as beneficial, "it would have been a little beneficial for some clients to have more group tasks" (S86). 


\section{SPEECH PATHOLOGY STUDENTS' PERCEIVED LEARNING OUTCOMES}

\section{Table 4}

Categories, Sub-categories and Codes From Student Responses to Post-program Survey Questions "What Did You Like Least About the Program?" and "How Do You Think the Program Could Be Improved?"

\begin{tabular}{|c|c|c|}
\hline \multirow{2}{*}{$\begin{array}{l}\text { Category } \\
\text { Sub-categories }\end{array}$} & \multicolumn{2}{|c|}{ Did not like some elements of the program's format $(n=42)$} \\
\hline & $\begin{array}{l}\text { Did not like the amount of preparation prior to } \\
\text { the program }(n=16)\end{array}$ & $\begin{array}{l}\text { Did not like some aspects of the program's } \\
\text { design }(n=26)\end{array}$ \\
\hline Codes & $\begin{array}{l}\text { Did not like feeling unprepared and wanted } \\
\text { more training }(n=16)\end{array}$ & $\begin{array}{l}\text { Did not like how the program felt rushed } \\
\text { ( } n=11) \\
\text { Intensity of the program was tiring and } \\
\text { stressful }(n=8) \\
\text { Working in groups was beneficial for clients } \\
\text { but not always for students }(n=4) \\
\text { Did not like limited time to plan with student } \\
\text { partner }(n=3)\end{array}$ \\
\hline Category & Improvements to program's content and tir & $=80)$ \\
\hline Sub-categories & Make changes to program content $(n=52)$ & $\begin{array}{l}\text { Make changes to program length and timing } \\
(\mathrm{n}=28)\end{array}$ \\
\hline Codes & $\begin{array}{l}\text { Redesign the training day }(n=23) \\
\text { Provide more information to students }(n=10) \\
\text { Include more group work }(n=8) \\
\text { Include more client interaction }(n=4) \\
\text { Other additions to program }(n=7)\end{array}$ & $\begin{array}{l}\text { Extend the length of the program }(n=16) \\
\text { Alter timing within the program days }(n=12)\end{array}$ \\
\hline
\end{tabular}

Note: Numbers in brackets are the number of condensed meaning units per category, sub-category and code. 


\section{Discussion}

This mixed-methods study examined student learning outcomes following participation in a 2-day fluency booster program. Students in this study reported statistically significant changes in perceived confidence, knowledge, interest and anxiety. These outcomes were further supported by qualitative responses, where students reported satisfaction with the learning opportunities provided throughout the program, with the program's format and with the support provided throughout the program. Findings from this study build on previous research by determining that student participation in intensive programs, even of short duration, has the capacity to improve their selfreported learning outcomes.

Student participants reported significantly improved confidence levels on all specified skills. These findings concur with those of Cardell and Hill (2013), who reported similar improvements in student confidence after participation in a 5-day intensive fluency clinic. Research in other health domains has similarly reported increases in student confidence following participation in a placement or clinical experience (AlSagarat et al., 2015; Hatton \& Mandrusiak, 2018; Porter et al., 2013). In the current study, interacting directly with AWS and observing their improvements may have contributed to this change in confidence, a concept supported by research suggesting that direct clinical experience can increase self-efficacy of clinicians working with those who stutter (Pasupathy \& Bogschutz, 2013). Survey and qualitative data in the current study support the notion that students perceive a benefit in practical experience working with AWS.

Students reported the greatest change in pre- and post-program confidence levels related to smooth speech skills. While the opportunity to use smooth speech techniques within the program might have facilitated the change in confidence due to increased clinical self-efficacy (Pasupathy \& Bogschutz, 2013), this notion is not consistently supported throughout the literature. A study by Lee (2014) reported that increased stuttering clinical experience negatively impacted some clinicians' and students' perceived comfort providing stuttering therapy. Lee (2014) alluded to the possibility that increased exposure to stuttering highlighted knowledge gaps that decreased comfort levels. These results highlight that confidence regarding therapy may not depend solely on having a clinical experience or on its duration, but rather on its nature. Therefore, the current study's finding that a 2-day program is an effective model for improving student confidence regarding smooth speech should be further explored related to clinical experiences in stuttering with alternative content.

Students' reported levels of knowledge improved significantly from pre- to postprogram in all measured areas, and students enjoyed the increased knowledge the program provided. Of note, pre-program ratings across six areas of knowledge ranged between "some knowledge" and "quite a bit of knowledge", suggesting that students had adequate initial knowledge, potentially due to classroom experiences. Previous fluency research also identified that students felt they had adequate theoretical knowledge about stuttering without having completed a fluency placement (Cardell 
\& Hill, 2013; Koutsodimitropoulos et al., 2016). As speech pathology students are reported to have a preference for learning through "concrete" or practical experiences (T. Brown et al., 2008) and feel these experiences are key to building knowledge in fluency (Koutsodimitropoulos et al., 2016), high quality practical clinical education experiences, such as the fluency booster program, are an appropriate means for increasing student knowledge for working with AWS.

Statistically significant gains were seen in student interest levels for working with AWS from attending this 2-day program, an outcome comparable with gains reported following a 5-day program (Cardell \& Hill, 2013). Students' pre-program moderate level of interest may be explained by their status as volunteers in the program, therefore, self-selecting potentially due to pre-existing interest. Fluency interest improved in post-program measures, in line with research suggesting that participation in clinical placements increases student interest in a particular area (O'Brien et al., 2008). A study by Reeve et al. (2012) found that physiotherapy students' interest to work in a particular area was influenced by the clinical exposure students obtained in that area. Increased student interest could potentially lead to increased numbers of clinicians who practise in this area. This is a promising outcome, given the prevalence of stuttering and clinicians' reported low confidence and comfort working in this area (Lee, 2014; Mavis et al., 2013). Future research should determine whether students who obtain practical fluency experience as a student work with AWS as graduate speech pathologists.

Participation in the booster program resulted in a statistically significant decrease in students' perceived anxiety. This result concurs with findings by Cardell and Hill (2013), suggesting comparable decreases in anxiety can be seen following the booster and 5-day intensive fluency programs. Qualitative responses revealed that scaffolding and support provided throughout the program was valued by the students, potentially contributing to the change in anxiety levels. Support and mentoring from peers and clinical educators, and clearly understanding a program's structure, are reported to decrease student anxiety within the clinical learning environment (Brumfitt \& Freeman, 2007; Moscaritolo, 2009). In the current study, students disliked feeling "unprepared" at the beginning of the program and recommended a redesign of the training day to alleviate this. Students' general satisfaction with the program's support and structure suggests that student anxiety levels can decrease, even if they initially feel unprepared, provided these supportive structures are in place. Given this decreased anxiety and the increased interest, confidence and knowledge reported by students in this study, the fluency booster program may be a more time- and cost-effective model than a 5-day intensive model. This study did not explore client perceptions and outcomes or clinical educator perceptions, which offer opportunities for further research.

The outcomes of this study may provide insight into considerations for development of clinical experiences for students in other health disciplines. Specifically, this study's finding that a learning experience of a shorter duration may have similar outcomes to those achieved from longer experiences may provide support for implementation of experiences that are more time- and cost-effective for both staff and students. Provision of shorter clinical experiences may still assist in alleviating placement shortages that are 
reported across the health sector (Taylor et al., 2017) and may be sufficient to increase students' interest and decrease their anxiety related to future employment within that caseload or context.

This study has some limitations. Firstly, results from this study may not be fully representative of broader student cohorts, as it included volunteer students and not students on assessed clinical placements. Additionally, students' perceptions of their confidence and knowledge in the area of fluency may not translate into clinical competency. Future research could investigate student competency outcomes. Finally, while the presence of qualitative data adds greater depth to the study, the four openended questions did not allow for deep qualitative analysis. Future research could use focus group methodology to enable deeper exploration of student perceptions of individual aspects of the booster program and the contribution of the pre-program training to their perceived learning outcomes.

\section{Conclusion}

This research has demonstrated that a 2-day fluency booster program has the capacity to improve students' perceived confidence, knowledge and interest whilst decreasing anxiety associated with working with AWS. These results are comparable to other 5-day intensive fluency clinics (Cardell \& Hill, 2013). While students reported that they liked the learning, support and format of the program, some wished the program were longer. Despite this, quantitative data indicate that positive self-reported learning outcomes can be obtained from shorter programs, which serve as more time- and cost-effective options for clients, clinicians and students. Outcomes of this study may inform the development of suitable clinical experiences for students in other health disciplines.

\section{Funding and conflicts of interest statement}

This research did not receive any specific grant from funding agencies in the public, commercial or not-for-profit sectors. The authors report no conflicts of interest. The authors alone are responsible for the content and writing of the paper.

\section{Acknowledgements}

The authors would like to thank the student participants, Professor Elizabeth Cardell and Ms Emma Bray for their contribution to this research study.

\section{References}

Al-Sagarat, A. Y., Al-Saraireh, F., Masa'deh, R., \& Moxham, L. (2015). The impact of a mental health clinical placement on the clinical confidence of nursing students in Jordan. Nurse Education Today, 35(6), 760-764. https://doi.org/10.1016/j. nedt.2015.02.008

Bandura, A. (1977). Self-efficacy: Toward a unifying theory of behavioural change. Psychological Review, 84, 191-215. https://doi.org/10.1037/0033-295X.84.2.191 
Beilby, J. (2014). Psychosocial impact of living with a stuttering disorder: Knowing is not enough. Seminars in Speech and Language, 35(2), 132-143. https://doi. org/10.1055/s-0034-1371756

Block, S., Onslow, M., Packman, A., Gray, B., \& Dacakis, G. (2005). Treatment of chronic stuttering: Outcomes from a student training clinic. International Journal of Language \& Communication Disorders, 40(4), 455-466. https://doi. org/10.1080/03093640500088161

Blumgart, E., Tran, Y., \& Craig, A. (2010). Social anxiety disorder in adults who stutter. Depression and Anxiety, 27(7), 687-692. https://doi.org/10.1002/da.20657

Brown, L., Wilson, L., Packman, A., Halaki, M., Onslow, M., \& Menzies, R. (2016). An investigation of the effects of a speech-restructuring treatment for stuttering on the distribution of intervals of phonation. Journal of Fluency Disorders, 50, 13-22. https://doi.org/10.1016/j.jfludis.2016.09.001

Brown, T., Cosgriff, T., \& French, G. (2008). Learning style preferences of occupational therapy, physiotherapy and speech pathology students: A comparative study. The Internet Journal of Allied Health Sciences and Practice, 6(3), 1-12.

Brumfitt, S., \& Freeman, M. (2007). Speech and language therapy students' perceptions of learning in a university clinical setting. Learning in Health and Social Care, 6(4), 231-244. https://doi.org/10.1111/j.1473-6861.2007.00160.x

Cardell, E., \& Hill, A. (2013). Student-delivered intensive smooth speech programs for adolescents and adults who stutter. Journal of Clinical Practice in SpeechLanguage Pathology, 15(2), 54-59.

Crichton-Smith, I., Wright, J., \& Stackhouse, J. (2003). Attitudes of speech and language therapists towards stammering: 1985 and 2000. International Journal of Language \& Communication Disorders, 38(3), 213-234. https://doi. org/10.1080/1368282031000086282

Cocks, N., Harding, C., \& Pritchard, M. (2014). The benefits of a 5-day dysphagia intensive placement. International Journal of Speech-Language Pathology, 16(5), 476-485. https://doi.org/10.3109/17549507.2013.826283

Craig, A., Blumgart, E., \& Tran, Y. (2009). The impact of stuttering on the quality of life in adults who stutter. Journal of Fluency Disorders, 34(2), 61-71. https://doi. org/10.1016/j.jfludis.2009.05.002

Craig, A., Hancock, K., Tran, Y., Craig, M., \& Peters, K. (2002). Epidemiology of stuttering in the community across the entire life span. Journal of Speech, Language, and Hearing Research, 45(6), 1097-1105. https://doi.org/10.1044/10924388(2002/088)

Creswell, J. W., Clark, V. L. P., Gutmann, M. L., \& Hanson, W. E. (2002). Advanced mixed methods research designs. In C. B. Teddlie \& A. M. Tashakkori (Eds.), Handbook of mixed methods in social \& behavioural research (pp. 209-240). Sage. 
Flasch, P., Taylor, D., Clauber, R. N., \& Robinson, E. (2017). Examining students' self-perceived competence and comfort in an experiential play therapy counseling course: A single group pretest-posttest investigation. International Journal for the Scholarship of Teaching and Learning, 11(1), 1-6. https://doi.org/10.20429/ ijsotl.2017.110110

Graneheim, U. H., \& Lundman, B. (2004). Qualitative content analysis in nursing research: Concepts, procedures and measures to achieve trustworthiness. Nurse Education Today, 24(2), 105-112. https://doi.org/10.1016/j.nedt.2003.10.001

Hatton, A. L., \& Mandrusiak, A. (2018). A single clinical experience in a nursing home improves physiotherapy students' attitudes towards, and confidence to communicate with, older people. Physical \& Occupational Therapy in Geriatrics, 36(2-3), 168-178. https://doi.org/10.1080/02703181.2018.1449164

Health Workforce Australia (HWA). (2014). Australia's health workforce series: Speech pathologists in focus. Author.

Irani, F., Gabel, R., Daniels, D., \& Hughes, S. (2012). The long term effectiveness of intensive stuttering therapy: A mixed methods study. Journal of Fluency Disorders, 37, 164-178. https://doi.org/10.1016/j.jfludis.2012.04.002

Kelly, E. M., Martin, J. S., Baker, K. E., Rivera, N. I., Bishop, J. E., Krizizke, C. B., Stettler, D. S., \& Stealy, J. M. (1997). Academic and clinical preparation and practices of school speech-language pathologists with people who stutter. Language, Speech and Hearing Services in Schools, 28(3), 195-212. https://doi. org/10.1044/0161-1461.2803.195

Klein, J. F., \& Hood, S. B. (2004). The impact of stuttering on employment opportunities and job performance. Journal of Fluency Disorders, 29(4), 255-273. https://doi.org/10.1016/j.jfludis.2004.08.001

Koutsodimitropoulos, E., Buultjens, M., St.Louis, K. O., \& Monfries, M. (2016). Speech pathology student clinican attitudes and beliefs towards people who stutter: A mixed-method pilot study. Journal of Fluency Disorders, 47, 38-55. https://doi.org/10.1016/j.jfludis.2015.12.003

Lee, K. (2014). Korean speech-language pathologists' attitudes toward stuttering according to clinical experiences. International Journal of Language \& Communication Disorders, 49(6), 771-779. https://doi.org/10.1111/14606984.12093

Mavis, I., St. Louis, K. O., Ozdemir, S., \& Togram, B. (2013). Attitudes of Turkish speech and language therapists toward stuttering. Journal of Fluency Disorders, 38(2), 157-170. https://doi.org/10.1016/j.jfludis.2013.03.002

Menzies, R. G., Onslow, M., Packman, A., \& O'Brian, S. (2009). Cognitive behaviour therapy for adults who stutter: A tutorial for speech-language pathologists. Journal of Fluency Disorders, 34(3), 187-200. https://doi. org/10.1016/j.jfludis.2009.09.002 
Moscaritolo, L. M. (2009). Interventional strategies to decrease nursing student anxiety in the clinical learning environment. Journal of Nursing Education, 48(1), 17-23. https://doi.org/10.3928/01484834-20090101-08

O'Brien, L., Buxton, M., \& Gillies, D. (2008). Improving the undergraduate clinical placement experience in mental health nursing. Issues in Mental Health Nursing, 29(5), 505-522. https://doi.org/10.1080/01612840801981355

Onslow, M., Jones, M., Menzies, R., O'Brian, S., \& Packman, A. (2012). Stuttering. In M. Hersen \& P. Sturmey (Eds.), Handbook of evidence-based practice in clinical psychology (Vol. 1, pp. 185-208). Wiley.

Park, S., Theodoros, D., Finch, E., \& Cardell, E. (2015). Be clear: A new intensive speech treatment for adults with nonprogressive dysarthria. American Journal of Speech-Language Pathology, 25(1), 97-114. https://doi.org/10.1044/2015_ AJSLP-14-0113

Pasupathy, R., \& Bogschutz, R. J. (2013). An investigation of graduate speechlanguage pathology students' SLP clinical self-efficacy. Contemporary Issues in Communication Science and Disorders, 40, 151-159.

Porter, J., Morphet, J., Missen, K., \& Raymond, A. (2013). Preparation for highacuity clinical placement: Confidence levels of final-year nursing students. Advances in Medical Education and Practice, 4, 83-89. https://doi.org/10.2147/ AMEP.S42157

Reeve, J., Skinner, M., Lee, A., Wilson, L., \& Alison, J. A. (2012). Investigating factors influencing 4th-year physiotherapy students' opinions of cardiorespiratory physiotherapy as a career path. Physiotherapy Theory and Practice, 28(5), 391-401. https://doi.org/10.3109/09593985.2011.619249

Rodriguez, A. D., Worrall, L., Brown, K., Grohn, B., McKinnon, E., Pearson, C., Van Hees, S., Roxbury, T., Cornwell, P., MacDonald, A., Angwin, A., Cardell, E., Davidson, B., \& Copland, D. A. (2013). Aphasia LIFT: Exploratory investigation of an intensive comprehensive aphasia programme. Aphasiology, 27(11), 13391361. https://doi.org/10.1080/02687038.2013.825759

Rose, M. L., Cherney, L. R., \& Worrall, L. E. (2013). Intensive comprehensive aphasia programs: An international survey of practice. Topics in Stroke Rehabilitation, 20(5), 379-387. https://doi.org/10.1310/tsr2005-379

Speech Pathology Australia (SPA). (2018). Clinical education in Australia: Building a profession for the future. Author.

Taylor, C., Angel, L., Nyanga, L., \& Dickson, C. (2017). The process and challenges of obtaining and sustaining clinical placements for nursing and allied health students. Journal of Clinical Nursing, 26, 3099-3110. https://doi.org/10.1111/ jocn. 13658

The Senate. (2014). Prevalence of different types of speech, language and communication disorders and speech pathology services in Australia. Parliament of Australia. https:// www.aph.gov.au/Parliamentary_Business/Committees/Senate/Community_ Affairs/Speech_Pathology/Report 